\title{
Prevalence of Violence among High School Students in Hat Yai Municipality, Southern Thailand: ICAST-CI Thai Version Study
}

\author{
Sasivara Boonrusmee, M.D. ${ }^{1}$, Tansit Saengkaew, M.D. ${ }^{1}$, Nannapat Pruphetkaew, M.Sc. ${ }^{2}$, \\ Somchit Jaruratanasirikul, M.D. ${ }^{1}$
}

'Department of Pediatrics, ${ }^{2}$ Epidemiology Unit, Faculty of Medicine, Prince of Songkla University, Hat Yai, Songkhla 90110, Thailand. Received 12 January 2018 • Revised 17 July 2018 • Accepted 26 July 2018 • Published online 7 September 2018

\section{Abstract:}

Objective: To determine the prevalence and risk factors of school violence among Thai high school students using a Thai version of the International Society for the Prevention of Child Abuse and Neglect (ISPCAN) Child Abuse Screening Tool-Children: Institute Version (ICAST-CI).

Material and Methods: A cross-sectional study was conducted at two high schools in Hat Yai municipality, Songkhla, southern Thailand with 480 students. Univariate logistic regression analysis was used to assess the risk factors associated with school violence.

Results: Overall, $88.8 \%$ of the students reported experiencing violence at school in their lifetimes. The prevalences of psychological, physical and sexual violence were $84.0 \%, 66.9 \%$ and $30.6 \%$, respectively. The most commonly reported violence patterns among each form of violence were swearing (87.8\%), slapping on hand/arm (66.4\%), and showing pornography (67.3\%), respectively. Students with good school performance tended to report psychological violence [odds ratio $(O R)=3.03,95 \%$ confidence interval $(C l)=1.13-8.07]$ whereas students aged $>15$ years were less likely to report physical violence $(\mathrm{OR}=0.47,95 \% \mathrm{Cl}=0.31-0.71)$. Sexual violence was reported more among male students $(\mathrm{OR}=1.71,95 \% \mathrm{Cl}=$ 1.12-2.61) and students aged $>15$ years regardless of gender $(\mathrm{OR}=1.58,95 \% \mathrm{Cl}=1.04-2.39)$. Students were more likely to be reported as a perpetrator than teachers in most patterns of violence.

Conclusion: The prevalence of school violence among high school students in Hat Yai municipality, southern Thailand, is significant. and the patterns of violence are similar to other ICAST-CI studies. Violence at school should be recognized as a serious problem, and preventive measures should be implemented nationwide.

Keywords: physical violence, psychological violence, school violence, sexual violence victimization

Contact: Somchit Jaruratanasirikul, M.D.

Department of Pediatrics, Faculty of Medicine, Prince of Songkla University,

Hat Yai, Songkhla, 90110 Thailand

E-mail: somchit.j@psu.ac.th
J Health Sci Med Res 2018;36(4):247-257 DOI: http://dx.doi.org/10.31584/jhsmr.2018.36.4.20 www.jhsmr.org 


\section{Introduction}

According to the 2002 World Health Organization Report on Violence and Health ${ }^{1}$ and the 2006 United Nations World Report on Children and Violence, ${ }^{2}$ youth violence, including verbal, psychological, physical and sexual violence, is a serious and growing global problem. Each year, millions of children around the world are victims and witnesses of violence. Most children spend more time at school than any other place besides their home, so it is worth exploring violence among children at schools. There have been numerous studies on many aspects of violence among children at schools in different parts of the world, with significant varying prevalence estimations of violence and violence-associated factors depending on study definitions, measurements, sample characteristics, and methodologies.

In Thailand, there have been studies regarding violence in adolescents at schools using various questionnaires such as the Thai Global School-Based Health Survey (Thai GSBS) ${ }^{3}$ and a structured self-report questionnaire. ${ }^{4}$ The prevalences of violence in these Thai studies have varied from $27.8 \%$ to $80.7 \%$ with these studies using different types of questionnaires and from different study regions. The highest rate of violence prevalence was reported to be in southern Thailand. ${ }^{4}$

In 2009, the International Society for the Prevention of Child Abuse and Neglect (ISPCAN) Child Abuse Screening Tool-Children: Institute Version (ICAST-CI) was developed in accordance with the United Nations Study on Violence against Children in order to have a tool to compare prevalence rates of violence internationally. ${ }^{5}$ The aim of our study was to use a Thai language version of the ICAST-CI to explore the prevalence and associated risk factors of physical, psychological and sexual violence occurring among high school students in the largest city in southern Thailand.

\section{Material and Methods}

The ICAST-Cl is used to record the forms, patterns, frequency, and perpetrators of violence experienced by students during the previous year and over the student's lifetime. The ICAST-CI consists of 3 sections based on the 3 most common forms of violence exposure high school students are likely to encounter, with 17 questions on physical violence, 14 questions on psychological violence and 10 questions on sexual violence. The students were asked to report each violence exposure based on their experience in the past year as many times, sometimes, never, or not in the past year but this has happened before. After permission was received from the ISPCAN, the questionnaire was translated into Thai and then backtranslated to ensure accuracy. The draft questions were reviewed by 2 high school teachers, 1 psychologist, 1 social worker and 1 physician with expertise in child and adolescent psychiatry to ensure that the questionnaire would be developmentally and culturally appropriate for Thai students. The questionnaire was then pretested in a sample of 200 high school students and appropriate adjustments were made. The internal consistency reliability of the questionnaire was rated with an overall Cronbach's alpha score of 0.87 while the subscales on physical abuse, psychological abuse and sexual abuse were $0.73,0.83$, and 0.55 respectively.

The study was conducted at 2 out of 8 high schools (grades 10-12) in Hat Yai municipality, Songkhla, southern Thailand from December 1, 2011 to February 28, 2012. The schools were randomly selected using proportionalto-size sampling and classes were randomly selected in the selected schools. An information sheet explaining the objectives and the method of the study was given to teachers, parents and students 2 weeks before the researchers' visit to the schools and informed consent was received from the school principals, students' parents, and the students. On the day of data collection, one member of the team explained the questionnaire and the 
process in the selected classroom. The anonymous, selfadministered questionnaires were handed over to students and they were completed individually within 30 minutes by all students who agreed to participate. The students were assured of confidentiality and encouraged to respond truthfully. Also, they could withdraw their participation at any time. The study was reviewed and approved by the Human Research Ethics Committee, Faculty of Medicine, Prince of Songkla University (EC: 54-069-01-1-3-4).

\section{Data analysis}

Statistical analysis was performed using the $R$ program software $v$ 2.14.1 (R Foundation for Statistical Computing, Vienna, Austria). A pattern of violence in the past year reported as either "many times" or "sometimes" was considered a "yes" answer for past year exposure while lifetime exposure was counted as a "yes" if "not in the past year but it had happened before" was checked. Descriptive analysis was performed on the students' socio-demographics and associations between the characteristics of the students and each victimization type were tested by chi-square. Univariate logistic regression analysis was used to determine associations between risk factors and the likelihood of victimization. The results are presented as odds ratios (OR) with 95\% confidence intervals $(\mathrm{Cl})$. Statistical differences were deemed significant at a $p$-value $<0.05$.

\section{Resullts}

Four hundred and eighty students participated in the study, 130 male (27.1\%) and 350 female $(72.9 \%)$. The proportion of female students was higher which corresponded with the approximate male-female ratio in the schools. The median age of the students was 16 years (IQR 13.1, 17.0). Of the total, 93.3\% were Buddhists and $82.0 \%$ of the students' parents were married. Overall, 426 students $(88.8 \%)$ reported experiencing violence or being victimized at school in their lifetime. 267 students
$(55.6 \%)$ gave their grade point average (GPA). The sociodemographic characteristics of the students who were victimized and not victimized were not significantly different as shown in Table 1.

\section{Prevalence of violence in schools}

Of the total 480 students, $426(88.8 \%)$ reported being victimized by at least one form of violence in their lifetime and 420 students (87.5\%) reported being victimized in the past year. Psychological violence was the most commonly reported for lifetime exposure $(83.9 \%)$, while physical violence and sexual violence were $66.9 \%$ and $30.7 \%$, respectively. Past year exposure for psychological, physical and sexual violence was $82.5 \%$, $62.9 \%$ and $28.1 \%$, respectively. Patterns of victimization and the numbers of students reporting each pattern regardless of frequency of being victimized were essentially consistent between lifetime and past year victimization as displayed in descending order along with the type of perpetrators of each pattern of violence in Table 2.

\section{Risk factors of school violence}

The associations between the socio-demographic factors of the students who reported each form of violence are shown in Table 3. Physical violence was significantly reported by students aged 15 years and younger, while psychological violence was reported significantly in students with GPA 3.00 and over, and sexual violence was reported significantly in male students and students aged older than 15 years. Table 4 shows the odds ratios with $95 \% \mathrm{Cl}$ for the association of risk factors and violence exposure. Students older than 15 years old had about a 50 percent lower probability of reporting physical violence. The students with higher GPAs had 3 times the odds of reporting psychological violence. Regarding sexual violence, male students and students older than 15 years of age, regardless of gender, had 1.7 times and 1.6 times the odds of reporting sexual violence, respectively. 
Table 1 Socio-demographic data of participants

\begin{tabular}{|c|c|c|c|c|}
\hline Variable & Number (\%) & No victimization (\%) & Victimization (\%) & P-value \\
\hline Total & 480 & $54(11.2)$ & $426(88.8)$ & \\
\hline Gender & & & & 0.18 \\
\hline Male & $130(27.1)$ & 7.7 & 92.3 & \\
\hline Female & $350(72.9)$ & 12.6 & 87.4 & \\
\hline Age (years) & & & & 0.06 \\
\hline Median (IQR) & $16(13.5,17.1)$ & $16(13.3,17.0)$ & $16(14.7,17.2)$ & \\
\hline Religion & & & & 0.85 \\
\hline Buddhist & $448(93.4)$ & 11.6 & 88.4 & \\
\hline Islam & $28(5.8)$ & 7.1 & 92.9 & \\
\hline Christian & $4(0.8)$ & 0.0 & 100.0 & \\
\hline Family income/month (baht) $(n=407)$ & & & & 0.83 \\
\hline$<10,000$ & $134(32.9)$ & 11.9 & 88.1 & \\
\hline $10,000-20,000$ & $142(34.9)$ & 12.0 & 88.0 & \\
\hline$>20,000$ & $131(32.2)$ & 9.9 & 90.1 & \\
\hline Father's education $(n=407)$ & & & & 0.49 \\
\hline Primary school & $85(20.9)$ & 9.4 & 90.6 & \\
\hline Secondary school & $160(39.4)$ & 12.5 & 87.5 & \\
\hline Vocational college & $50(12.4)$ & 6.0 & 94.0 & \\
\hline Bachelor degree or more & $112(27.3)$ & 13.4 & 86.6 & \\
\hline Mother's education $(n=407)$ & & & & 0.79 \\
\hline Primary school & $127(31.2)$ & 11.0 & 89.0 & \\
\hline Secondary school & $137(33.6)$ & 10.2 & 89.8 & \\
\hline Vocational college & $52(12.8)$ & 15.4 & 84.6 & \\
\hline Bachelor degree or more & $91(22.4)$ & 11.0 & 89.0 & \\
\hline Family structure $(n=473)$ & & & & 0.76 \\
\hline Married & $388(82)$ & 11.3 & 88.7 & \\
\hline Widowed/divorced & $67(14.2)$ & 10.4 & 89.6 & \\
\hline One parent passed away & $18(3.8)$ & 11.0 & 89.0 & \\
\hline Grade point average $(n=267)$ & & & & 0.06 \\
\hline$<3.00$ & $190(71.2)$ & 14.2 & 85.8 & \\
\hline$\geq 3.00$ & $77(28.8)$ & 5.2 & 94.8 & \\
\hline
\end{tabular}

IQR=interquartile range 
Table 2 Patterns of victimization and perpetrators

\begin{tabular}{|c|c|c|c|c|c|}
\hline \multirow{3}{*}{ Details of violence } & \multicolumn{2}{|c|}{ Victimization } & \multicolumn{3}{|c|}{ Perpetrator } \\
\hline & Lifetime & Last year & Adult & Child & Both \\
\hline & Number (\%) & Number (\%) & $\%$ & $\%$ & $\%$ \\
\hline \multicolumn{6}{|l|}{ Physical violence } \\
\hline Slap on hand or arm & $213(66.4)$ & $197(41.0)$ & 32.5 & 42.1 & 25.4 \\
\hline Anyone hurt you & $113(35.2)$ & $85(17.7)$ & 9.2 & 75.2 & 15.6 \\
\hline Slap on head or face & 107 (33.3) & $83(17.3)$ & 20.8 & 54.5 & 24.7 \\
\hline Throw object at you & 107 (33.3) & $101(21.0)$ & 9.7 & 76.7 & 13.6 \\
\hline Kick you & $106(33.0)$ & $97(20.2)$ & 7.0 & 84.0 & 9.0 \\
\hline Pull hair & $99(30.8)$ & $92(19.2)$ & 31.2 & 54.8 & 14.0 \\
\hline Stand/Kneel for punishment & $91(28.3)$ & $75(15.6)$ & 82.1 & 7.1 & 10.8 \\
\hline Hit you & $68(21.2)$ & $57(11.9)$ & 14.1 & 76.6 & 9.3 \\
\hline Twist ear & $68(21.2)$ & $52(10.8)$ & 60.3 & 17.5 & 22.2 \\
\hline Crush fingers & $54(16.8)$ & $48(10.0)$ & 24.0 & 60.0 & 16.0 \\
\hline Stay out in cold or heat & $46(14.3)$ & $35(7.3)$ & 90.9 & 6.8 & 2.3 \\
\hline Choke you & $25(7.8)$ & $20(4.2)$ & 9.1 & 81.8 & 9.1 \\
\hline Cut you with sharp objects & $9(2.8)$ & $3(0.6)$ & 0.0 & 100.0 & 0.0 \\
\hline Wash your mouth with soap or pepper & $8(2.5)$ & $4(0.8)$ & 66.7 & 33.3 & 0.0 \\
\hline Burn & $7(2.2)$ & $2(0.4)$ & 0.0 & 66.7 & 33.3 \\
\hline Put you in cold or hot water & $5(1.6)$ & $2(0.4)$ & 50.0 & 50.0 & 0.0 \\
\hline Tie you up & $0(0.0)$ & $0(0.0)$ & 0.0 & 0.0 & 0.0 \\
\hline \multicolumn{6}{|l|}{ Psychological violence } \\
\hline Swear at you & $354(87.8)$ & $346(85.9)$ & 8.4 & 71.7 & 19.9 \\
\hline Insult you & $260(64.5)$ & $246(61.0)$ & 11.4 & 62.4 & 26.3 \\
\hline Call you rude or hurtful names & $212(52.6)$ & $200(49.6)$ & 6.3 & 83.4 & 10.2 \\
\hline Shout at you & $200(49.6)$ & $188(46.7)$ & 9.2 & 79.1 & 11.7 \\
\hline Make you feel stupid & $189(46.9)$ & $184(45.7)$ & 15.1 & 61.1 & 23.8 \\
\hline Hurtful prejudice (gender, ethnicity, etc) & $135(33.5)$ & $128(31.8)$ & 7.6 & 78.0 & 14.4 \\
\hline Steal or break belongings & $97(24.1)$ & $80(19.9)$ & 4.2 & 89.5 & 6.3 \\
\hline Hurtful prejudice against health problem & $62(15.4)$ & $58(14.4)$ & 6.6 & 77.0 & 16.4 \\
\hline Threaten you with bad marks & $40(9.9)$ & $32(7.9)$ & 11.1 & 77.8 & 11.1 \\
\hline Isolate you & $32(7.9)$ & $27(6.7)$ & 10.1 & 80.0 & 10.0 \\
\hline Make you do something dangerous & $20(5.0)$ & $15(3.7)$ & 17.6 & 52.9 & 29.4 \\
\hline Embarrass you b/c you are poor & $17(4.2)$ & $15(3.7)$ & 13.3 & 77.3 & 13.3 \\
\hline Take food away & $14(3.5)$ & $12(3.0)$ & 16.7 & 66.7 & 16.7 \\
\hline Embarrass you b/c you are orphan & $8(2.0)$ & $6(1.5)$ & 16.7 & 50.0 & 33.3 \\
\hline
\end{tabular}


Table 2 (continued)

\begin{tabular}{|c|c|c|c|c|c|}
\hline \multirow{3}{*}{ Details of violence } & \multicolumn{2}{|c|}{ Victimization } & \multicolumn{3}{|c|}{ Perpetrator } \\
\hline & Lifetime & Last year & Adult & Child & Both \\
\hline & Number (\%) & Number (\%) & $\%$ & $\%$ & $\%$ \\
\hline \multicolumn{6}{|l|}{ Sexual violence } \\
\hline Show you pornography & 99 (67.3) & $89(60.5)$ & 3.1 & 91.8 & 5.2 \\
\hline Touch you in a sexual way & $55(37.4)$ & $48(32.7)$ & 9.4 & 84.9 & 5.7 \\
\hline Unwanted touch to private parts & $38(25.9)$ & $31(21.1)$ & 0.0 & 100.0 & 0.0 \\
\hline Take their own clothes off & $17(11.6)$ & $13(8.8)$ & 21.4 & 78.6 & 0.0 \\
\hline Unwanted kiss & $13(8.8)$ & $10(6.8)$ & 0.0 & 100.0 & 0.0 \\
\hline Involve you in making pornography & $12(8.2)$ & $9(6.1)$ & 0.0 & 100.0 & 0.0 \\
\hline Make you touch their private parts & $10(6.8)$ & $7(4.8)$ & 12.5 & 87.5 & 0.0 \\
\hline Make you take off clothes & $7(4.8)$ & $4(2.7)$ & 25.0 & 50.0 & 25.0 \\
\hline Make you have sex with them & $7(4.8)$ & $4(2.7)$ & 20.0 & 60.0 & 20.0 \\
\hline Give you money for sexual things & $3(2.0)$ & $1(0.7)$ & 0.0 & 100.0 & 0.0 \\
\hline
\end{tabular}

Table 3 Associations between socio-demographic factors and lifetime-violence

\begin{tabular}{|c|c|c|c|c|c|c|}
\hline \multirow{2}{*}{ Socio-demographics } & \multicolumn{2}{|c|}{ Physical violence } & \multicolumn{2}{|c|}{ Psychological violence } & \multicolumn{2}{|c|}{ Sexual violence } \\
\hline & Positive (\%) & P-value & Positive (\%) & $\mathrm{P}$-value & Positive (\%) & P-value \\
\hline Total & 66.9 & & 83.9 & & 30.7 & \\
\hline Gender & & 0.15 & & 0.92 & & 0.02 \\
\hline Female & 64.9 & & 83.7 & & 27.4 & \\
\hline Male & 72.3 & & 84.6 & & 39.2 & \\
\hline Age (years) & & $<0.01$ & & 0.60 & & 0.04 \\
\hline$\leq 15$ & 77.0 & & 85.4 & & 24.7 & \\
\hline$>15$ & 60.9 & & 83.1 & & 34.1 & \\
\hline Religion & & 0.77 & & 0.37 & & 0.99 \\
\hline Buddhist & 67.0 & & 83.3 & & 30.8 & \\
\hline Islam & 67.9 & & 92.9 & & 28.6 & \\
\hline Christian & 50.0 & & 100.0 & & 25.0 & \\
\hline Family income/month (baht) & & 0.05 & & 0.96 & & 0.58 \\
\hline$<10,000$ & 69.4 & & 84.3 & & 30.6 & \\
\hline $10,000-20,000$ & 57.7 & & 84.5 & & 35.2 & \\
\hline$>20,000$ & 7.02 & & 85.5 & & 29.8 & \\
\hline
\end{tabular}


Table 3 (continued)

\begin{tabular}{|c|c|c|c|c|c|c|}
\hline \multirow{2}{*}{ Socio-demographics } & \multicolumn{2}{|c|}{ Physical violence } & \multicolumn{2}{|c|}{ Psychological violence } & \multicolumn{2}{|c|}{ Sexual violence } \\
\hline & Positive (\%) & P-value & Positive (\%) & P-value & Positive (\%) & P-value \\
\hline Father's education & & 0.12 & & 0.49 & & 0.45 \\
\hline Primary school & 56.5 & & 84.7 & & 30.6 & \\
\hline Secondary school & 67.5 & & 83.8 & & 30.6 & \\
\hline Vocational college & 76.0 & & 92.0 & & 42.0 & \\
\hline Bachelor degree or more & 65.2 & & 83.0 & & 30.4 & \\
\hline Mother's education & & 0.28 & & 0.77 & & 0.63 \\
\hline Primary school & 59.1 & & 85.8 & & 33.1 & \\
\hline Secondary school & 68.6 & & 83.9 & & 34.3 & \\
\hline Vocational college & 65.4 & & 80.8 & & 32.7 & \\
\hline Bachelor degree or more & 70.3 & & 86.8 & & 26.4 & \\
\hline Parental marital status & & 0.84 & & 0.48 & & 0.50 \\
\hline Married & 67.3 & & 83.2 & & 29.1 & \\
\hline Divorced & 65.7 & & 88.1 & & 34.3 & \\
\hline Widowed & 61.1 & & 77.8 & & 38.9 & \\
\hline Grade point average & & 0.97 & & 0.04 & & 0.86 \\
\hline$<3.00$ & 67.4 & & 82.6 & & 38.4 & \\
\hline$\geq 3.00$ & 66.2 & & 93.5 & & 36.4 & \\
\hline
\end{tabular}

Table 4 Associations between key variables and violence: univariate regression analysis

\begin{tabular}{|c|c|c|c|c|c|c|}
\hline \multirow{2}{*}{ Variables } & \multicolumn{2}{|c|}{ Physical violence } & \multicolumn{2}{|c|}{ Psychological violence } & \multicolumn{2}{|c|}{ Sexual violence } \\
\hline & OR $(95 \% \mathrm{Cl})$ & P-value & OR $(95 \% \mathrm{Cl})$ & P-value & OR $(95 \% \mathrm{Cl})$ & P-value \\
\hline \multicolumn{7}{|l|}{ Gender } \\
\hline Female & 1 & & 1 & & 1 & \\
\hline Male & $1.41(0.91-2.2)$ & 0.12 & $1.07(0.61-1.86)$ & 0.81 & $1.71(1.12-2.61)$ & 0.01 \\
\hline \multicolumn{7}{|l|}{ Age (years) } \\
\hline$\leq 15$ & 1 & & 1 & & 1 & \\
\hline$>15$ & $0.47(0.31-0.71)$ & $<0.01$ & $0.84(0.50-1.41)$ & 0.50 & $1.58(1.04-2.39)$ & 0.03 \\
\hline \multicolumn{7}{|c|}{ Grade point average } \\
\hline$<3.00$ & 1 & & 1 & & 1 & \\
\hline$\geq 3.00$ & $0.95(0.54-1.67)$ & 0.86 & $3.03(1.13-8.07)$ & 0.01 & $0.92(0.53-1.59)$ & 0.75 \\
\hline
\end{tabular}

$\mathrm{OR}=$ odds ratio, $\mathrm{Cl}=$ confidence interval 


\section{Discussion}

This is the first study in Thailand to use Thai version of the ICAST-CI to investigate the prevalence of school violence among high school students. The lifetime rates of physical, psychological and sexual victimization were $66.9 \%, 83.9 \%$ and $30.7 \%$, respectively. This high prevalence of school violence found in our study was similar to the study conducted by Ribeiro et al using the ICAST-CI questionnaire among 288 students in Brazil in which the prevalences of physical, psychological and sexual violence were $85.4 \%, 62.5 \%$ and $34.7 \%$, respectively. ${ }^{6}$ In contrast, the National Study on Violence against Children in Georgia $^{7}$ using the ICAST-Cl questionnaire to interview 1,300 students individually, lifetime prevalences of physical, psychological and sexual violence were $61.7 \%, 56.4 \%$ and $7.3 \%$, respectively, in which rates of psychological and sexual violence were much lower than our study. These differences could possibly be explained by the face-toface interviews of the Georgia students may have had the effect of making the students feel ashamed and/or unwilling to reveal their true experiences in sensitive issues.

In Thailand, in 2012, there was a national survey on violence in 6,345 high school students, using a Thai selfadministered questionnaire, conducted by the Office of Welfare Promotion and Protection of Children, the Elderly and Underprivileged Youth, Ministry of Social Development and Human Security. ${ }^{8}$ The Thai national survey, the Brazil study and the Georgia study were the most comparable studies we could find and the top 3 common patterns of victimization in lifetime among these studies are quite similar to our study as shown in Table 5.

In some situations, the patterns of reported physical and psychological violence may seem to be trivial and may be considered unintended by the perpetrators, however, the children's perceptions should not be overlooked. Behaviors that show impoliteness between students such as unprovoked offensive touching (throwing something at someone, pushing, grabbing, shoving, slapping, kicking, or hitting someone), verbal teasing, verbal intimidation, insulting or any actions perceived as offensive can be "opening moves" that initiate more violent incidents. ${ }^{9,10}$ Chen and Astor conducted a study on perpetration of school violence in Taiwan which revealed similar results to studies from western countries in which a majority of perpetrators reported the apparent violence stemmed from rough and tumble play or from situations where they were initially having fun. ${ }^{11}$ Students and teachers should consider these opening moves as inappropriate behaviors and it should be discouraged at schools.

We found that students older than 15 years were less likely to report physical victimization which is consistent with the study from Georgia and other studies which found that reported incidences of physical violence declined significantly with increasing age. ${ }^{12,13}$ However, there were no gender differences in our study, whereas the Georgia study and most studies have reported that males were more likely to report physical violence than females. ${ }^{4,12-15}$ We could not demonstrate an association between gender and physical violence because we had significantly fewer male students than females. In our study, the main factor associated with psychological violence was school performance, as students with higher GPAs were more likely to report psychological violence exposure. This finding is in contrast to most studies, which have found that violence was more likely to be linked to poor academic performance. ${ }^{15-18}$ We postulate that students with higher GPAs are more sensitive and more inclined to define some patterns of verbal aggression as intimidating or abusive, whereas students with lower GPAs may not perceive similar experiences as victimization. Further studies are needed to explore this issue, due to the small sample size of students who provided GPA results in our study. 


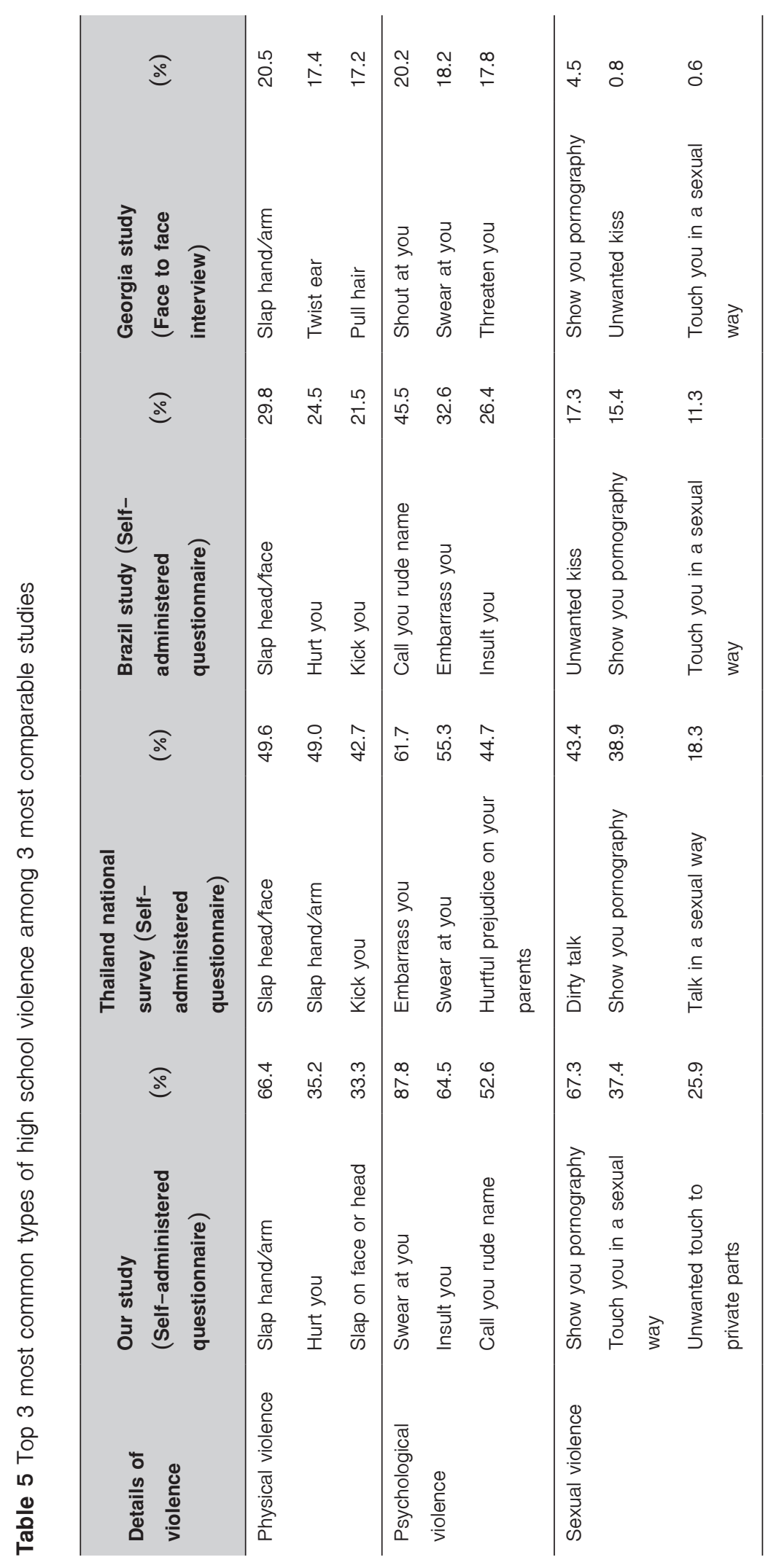


The high prevalence of sexual violence in our study was mainly related to the students being shown pornography. This finding corresponds closely to the findings of the other 3 studies as shown in Table 5 . In addition, univariate analysis found that males and students over 15 years of age regardless of gender were more likely to report sexual violence. A possible explanation for these high rates is that looking at or being shown pornography is a normal part of adolescent sexual development when curiosity along with peer pressure may drive adolescents to watch or look at pornographic materials. Other intrusive acts such as being touched in a sexual way, unwanted touching of the private parts, and unwanted kissing were less reported, but these acts should not be ignored since these types of inappropriate touching can lead to more intrusive sexual harassment.

Concerning the perpetrators of each pattern of violence, more students were reported as perpetrators than teachers in most cases, except for some patterns of physical violence. Making students stay outdoor in cold or hot weather, standing/kneeling for punishment and eartwisting were the 3 common patterns of violence perpetrated more by teachers, a finding which again was consistent with the Georgia study and the Brazil study. These patterns of physical punishment may seem trivial but they can lead to more severe patterns of teacher-student violence, including corporal punishment which has been deemed illegal in Thailand under the Ministry of Education Regulations on Student Punishment since 2005. ${ }^{19}$ However, some teachers are still not aware of the law and may not consider physical punishment to be a problem, particularly when no lasting physical injury happens and currently corporal punishment still persists in many schools in Thailand. ${ }^{20,21}$

Our study had some strength and limitations. The main strength is that it is the first study of school violence in Thailand using Thai version of the ICAST-Cl questionnaire, allowed our findings to be compared with studies from other countries which also used the ICAST-CI questionnaire. The main limitation is that it was conducted in only 2 schools and the participants were not balanced in gender distribution so it cannot be generalized to other student populations in other parts of the country.

\section{Conclusion}

This is the first study in Thailand using the ICAST$\mathrm{Cl}$ questionnaire to study school violence among high school students. Although this study does not provide nationally representative findings about the prevalence of violence against and among children at high schools, it clearly points to an alarming number of children who perceived that they were psychologically and/or physically hurt and/or exposed to sexual acts by other children and teachers. These psychological and physical maltreatment events may be termed trivial by some, but their incidence needs to be reduced to prevent escalation to more serious violence. Sexual maltreatment either by other students or teachers should be universally considered unacceptable and should be prevented in any educational setting.

\section{Acknowledgement}

This research was supported by the Research Funding Unit, Faculty of Medicine, Prince of Songkla University. The authors are grateful to the participants for agreeing to participate in the study, and the classroom teachers for their assistance with questionnaire distribution. The authors thank Mr. David Patterson from the International Affairs Office in the Faculty of Medicine, Prince of Songkla University, for editorial help.

\section{References}

1. World Health Organization. World report on violence and health [monograph on the Internet]. Geneva: WHO; 2002 [cited 2017 Sept 30]. Available from: http://www.who.int/ violence_injury_prevention/violence/world_report/en/ 
2. Pinheiro P. World report on violence against children [monograph on the Internet]. Geneva: ATAR Roto Presse SA; 2006 [cited 2017 Sept 30]. Available from: http://www.unicef.org/ violencestudy/

3. Pengpid S, Peltzer K. Bullying and its associated factors among school-aged adolescents in Thailand. Scientific World J 2013; 2013:2543083. DOI: 10.1155/2013/254083.

4. Pradubmook-Sherer P, Sherer M. In the shadow of terror: high school youth violence in Thailand. J Family Violence 2014;29: 783-95.

5. Zolotor AJ, Runyan DK, Dunne MP, Jain D, Peturs HR, Ramirez C, et al. ISPCAN Child Abuse Screening Tool Children's Version (ICAST-C): Instrument development and multi-national pilot testing. Child Abuse Negl 2009;33:833-41.

6. Ribeiro IMP, Ribeiro AST, Pratesi R, Gandolfi L. Prevalence of various forms of violence among school students. Acta Pau Enferm 2015;28:54-9.

7. Lynch MA, Saralidze L, Goduadze N, Zolotor A. National study on violence against children in Georgia [monograph on the Internet]. Tbilisi: Unicef Georgia; 2007 [cited 2017 Jan 31]. Available from: http://www.unicef.org/georgia/Niolence_Study_ ENG_final.pdf

8. Ministry of Social Development and Human Security, Thailand. National study on violence against children in Thailand: high school students. (Vol. 3). Bangkok: The Ministry; 2012.

9. Lockwood D. Violence among middle school and high schoo students: analysis and implications for prevention [homepage on the Internet]. Washington DC: US Department of Justice; 1997 [cited 2017 Jan 31]. Available from: https://www.ncjrs.gov/ pdffiles/166363.pdf

10. Skiba RJ, Peterson RL. School discipline at a crossroads: from zero tolerance to early response. Except Child 2000;66:33546.

11. Chen JK, Astor RA. The perpetration of school violence in Taiwan: an analysis of gender, grade level and school type. Sch Psychol Int 2009;30:568-84.
12. Chen JK, Astor RA. School violence in Taiwan: examining how western risk factors predict school violence in an Asian culture. J Interpers Violence 2010;25:1388-410.

13. Khoury-Kassabri M, Benbenishty R, Astor RA, Zeira A. The contributions of community, family, and school variables to student victimization. Am J Comm Psychol 2004;34:187-204.

14. Felix ED, Furlong MJ, Austin G. A cluster analytic investigation of school violence victimization among diverse students. J Interpers Violence 2009;24:1673-95.

15. Basch CE. Aggression and violence and the achievement gap among urban minority youth. J Sch Health 2011;81:619-25.

16. Stephenson R, Sheikhattari P, Assasi N, Eftekhar H, Zamani Q, Maleki B, et al. Child maltreatment among school children in the Kurdistan Province, Iran. Child Abuse Negl 2006;30:23145.

17. Devries KM, Child JC, Allen E, Walakira E, Parkes J, Naker D School violence, mental health, and educational performance in Uganda. Pediatrics 2014;133:e129-37.

18. Nakamoto J, Schwartz D. Is peer victimization associated with academic achievement? A meta-analytic review. Soc Dev 2010;19:221-42.

19. Global Initiative to End All Corporal Punishment of Children. Corporal punishment of children in Thailand [homepage on the Internet]. Bangkok: Unicef; 2016 [cited 2017 Feb 28] Available from: http://www.endcorporalpunishment.org/assets/ pdfs/states-reports/Thailand.pdf

20. Childline Thailand Foundation. Corporal punishment to inform the review of Thailand 2014 [homepage on the Internet]. Bangkok: The Foundation; 2014 [cited 2017 Feb 28]. Available from: http://tbinternet.ohchr.org/Treaties/CAT/Shared\%20 Documents/THA1NT_CAT_NGO_THA_17053_E.pdf

21. UN Children's Fund Thailand. UNICEF urges stronger enforcement of corporal punishment bans in schools [homepage on the Internet]. Bangkok: Unicef; 2014 [cited 2017 Feb 28]. Available from: http://www.unicef.org/thailand/media_14082. html 